\title{
DRIVING ENERGY CONSUMPTION OF ELECTRIC TRACTION VEHICLES
}

The paper presents some simulation and tests results of driving energy consumption of electric traction vehicles both at Serbian and Slovenian Railways. On Serbian Railways there are two series of electric locomotives: four-axles 441 series made in former Yugoslavia under license of ASEA (Sweden) and six-axles 461 series manufactured in Romania in co-operation with ASEA. On Slovenian railways are four series of electrical locomotives operating: the Italian two axles locomotive series 342, the Italian six axles locomotive series 362, the French six axles locomotive series 363, and the three-system four axles Siemens locomotive series 541.

Keywords: energy consumption, electric traction vehicles, Slovene railways, Serbian railways, GPS

\section{Introduction}

The problem of driving energy savings during train traction became very significant during the energetic crisis and therefore all foreign railways have conducted wide researches in order to find a solution of this problem. Apart from technical improvements of tractive and hauled stock these researches have also been conducted in the field of software development for finding optimal energetic train running trajectories. Considering the fact that the most of the driving energy rationalization possibilities have already been used the subject of the newest researches has become the way of train running (for the given line the running regimes with the low or the lowest possible energy consumption are chosen with all the other conditions defined by the timetable unchanged). With the optimal way of running it is possible for the train to run on the given line according to the given timetable and with minimal energy consumption. The optimization results are used for making and maintaining the optimal energy timetables.

In Serbia such work was done by the Institute of Transportation CIP (SI CIP) and verified on the Serbian Railway network (ZS) $[1,2]$.

The co-author in Slovenia is executing the inspectorial supervision of operation and maintenance of railway vehicles in Slovenia.

\section{The state of the electric traction vehicles} in Serbia and Slovenia

The first electric locomotive, 441 series (Fig. 1) (four-axle $B_{o}^{\prime} B_{o}^{\prime}$ ), was put in exploitation on the former Yugoslav Railways network in the mid of 1970. In 1971, a large number of them were

\footnotetext{
* Bojan Cene ${ }^{1}$, Aleksandar Radosavljevic ${ }^{2}$, Branislav Gavrilovic ${ }^{3}$

${ }^{1}$ Ministry for Traffic, Ljubljana, Slovenia, Email: bojan.cene@gmail.com

${ }^{2}$ Institute of Transportation CIP, Belgrade, Serbia

${ }^{3}$ Serbian Railways, Belgrade, Serbia
}

delivered for the same network. "Rade Koncar", the enterprise from Zagreb, manufactured those locomotives, licensed by ASEA, Sweden. Six-axle $\left(C_{o}^{\prime} C_{o}^{\prime}\right)$ electric locomotives, 461 series (Fig. 3), were manufactured in the mid of 1972 in Resice, Romania in cooperation with the ASEA. They were delivered for the "eastern" part of the former Yugoslav Railways (ZTP Belgrade, Skopje and Podgorica) [3].

The locomotives use single axle drive and diodes in drive control system. Electric locomotives series 441 are developed for speeds of 120 and $140 \mathrm{~km} / \mathrm{h}$ (the ratios between the cog number of the smaller and the larger cog-weel are 20:73 and 28:87) and series 461 for the speed of $120 \mathrm{~km} / \mathrm{h}$ only (20:73). The electric equipment is constructed to work with single-phase alternate current with nominal voltage of $25 \mathrm{kV}$ and frequency of $50 \mathrm{~Hz}$. Both series have two driver's cabs, one on each locomotive end, which are used on electrified lines for passenger and freight train traction.

30 diode electric locomotives series 441 had been modernized into thyristor locomotives series 444 (Fig. 2) between 2004 and 2007 in the company "Rade Koncar", Zagreb. New modern equipment is built into locomotives leading to improvements in performance, reliability and availability. Modernization had included substitution of all relay equipment with microprocessors for locomotive control, protection and diagnostic of malfunctioning with messages and instructions for maintenance. The old step regulation of traction motors was replaced with continuous control of tractive effort based on thyristor elements.

The following objectives are intended to be achieved by modernization: lifetime extension, improvement in service parameters, service cost reduction, better working environment for drivers, 
high unification of equipment on locomotives of series 441 and 461 and maintenance cost reduction. Total number of locomotive series 441 is 76 (441: 46, 444: 30$)$ and of series 461 is 53.

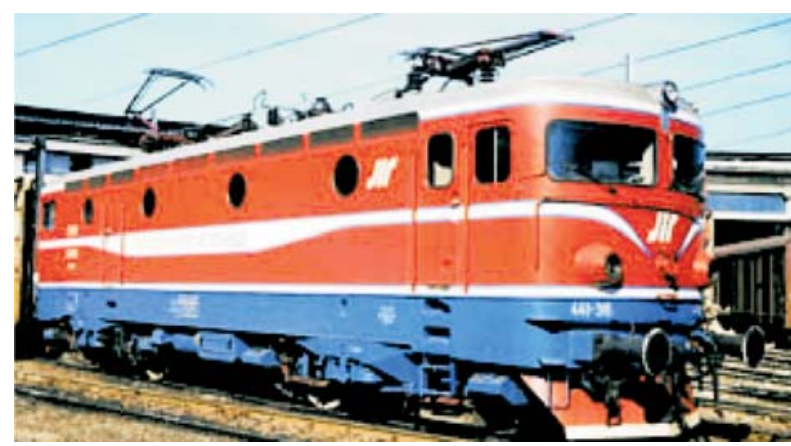

Fig. 1 The electric locomotive series 441

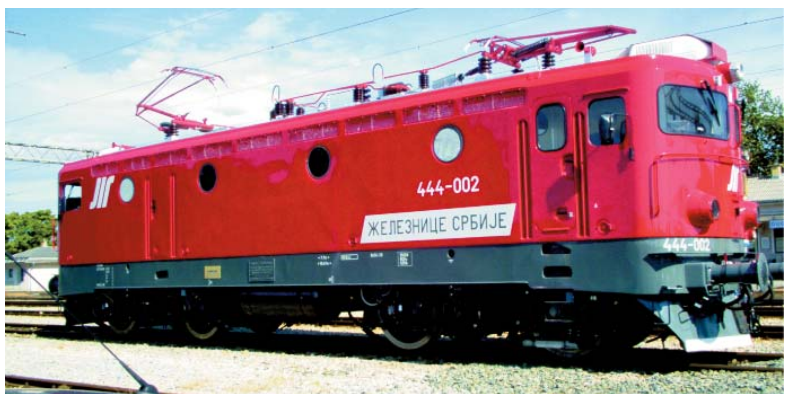

Fig. 2 The electric locomotive series 444

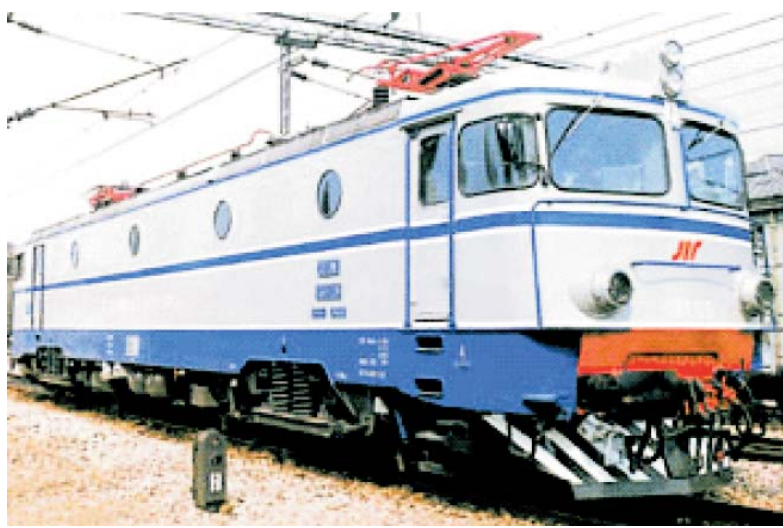

Fig. 3 The electric locomotive series 461

The fourth (four axles $B_{0}^{\prime} B_{0}^{\prime}$ locomotive of the DC System $3 \mathrm{kV}$, series 342 was manufactured by Ansaldo Italy and has been operating in the region of Slovenian Railways since the year 1968 (Fig. 4). The next (six axles $B_{0}^{\prime} B_{0}^{\prime} B_{0}^{\prime}$ ) DC system locomotive series 362 was also manufactured by Ansaldo Italy and has been already operating in Slovenia since the year 1960 (Fig. 5). The French locomotive (six axles $C^{\prime} C^{\prime}$ ) series 363 has been operating in Slovenia since the year 1975 and is still representing the most frequent electric locomotive on the Slovenian railways today (Fig. 6). In

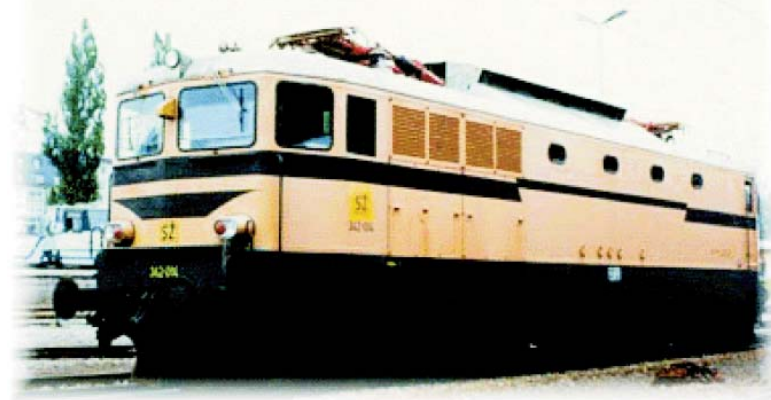

Fig. 4 The electric locomotive series 342

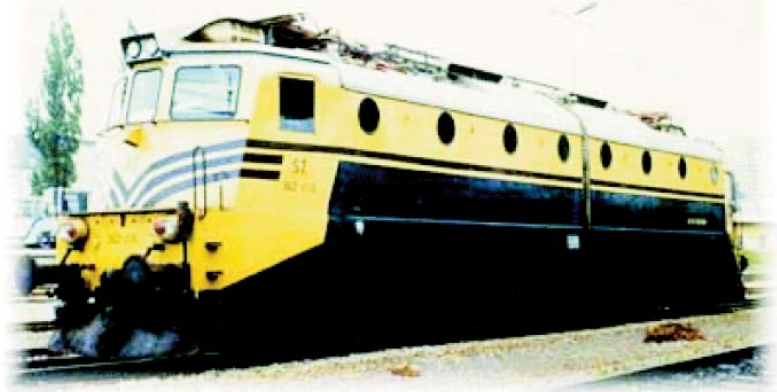

Fig. 5 The electric locomotive series 362

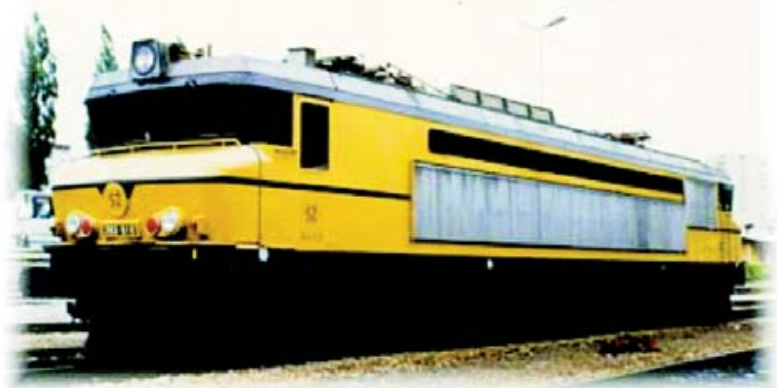

Fig. 6 The electric locomotive series 363

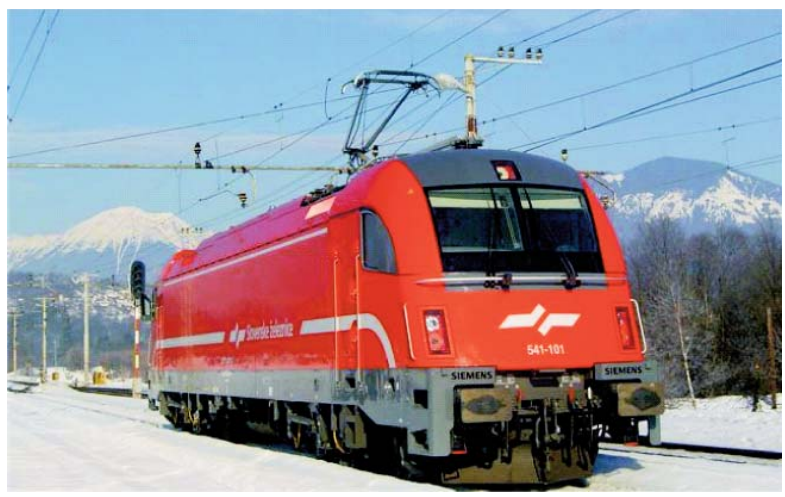

Fig. 7 The electric locomotive series 541 
the year 2006 in Slovenia started operating the three-system (four axles $B_{0}^{\prime} B_{0}^{\prime}$ ) Siemens electric locomotive series 541 , factory designated as ES64U4. It can operate in the following electric traction systems: DC system $3 \mathrm{kV}$, single phase AC system $25 \mathrm{kV}, 50 \mathrm{~Hz}$ and single phase $\mathrm{AC}$ system $15 \mathrm{kV}, 16$ 2/3 Hz (Fig. 7).

The Italian locomotives series 342, rated output $2 \mathrm{MW}$ and series 362 , rated output $2.65 \mathrm{MW}$ are classic resistance electric locomotives, which are slowly terminating their service in Slovenia. The locomotive 363 , rated output $2.75 \mathrm{MW}$ is a more up-todate resistance locomotive with gear transmission of power across a reduction gear to the wheel sets. This locomotive is still expected to operate for approximately ten more years. The Siemens locomotive series 541 is an interoperable locomotive and was acquired for operation on the railways in Slovenia as well as in neighbouring countries. It is equipped with static convertors in transistor version.

\section{Definition of the train movement differential equation}

Train movement equation represents the dependence between the train acceleration and the efforts exerted during the train running. The train movement equation is the basis for solving all the traction-energy tasks. Some of them are: running times, driving energy consumption, determination of the corresponding train load for the given line, determination of the optimal energy running times, etc. The train movement equation is based on the well-known mechanics rule: elementary work of efforts exerted on the running train (resultant efforts) is equivalent to the elementary increase (or decrease) of quantity of motion [1]:

$$
d A=d E
$$

Where: $d A[\mathrm{Nm}]$ - elementary work of the resultant effort; $d E$ $[\mathrm{Nm}]$ - elementary change of the live effort-train kinetic energy.

During running the train is exposed to influence of different efforts (considering the intensity and direction) but its movement is the result of influence of the resultant effort. When the train movement speed is changed the wheel rotating and rotating masses speeds that are rotating according to the train movement are also changed. Train movement equations are as follows:

$$
\begin{aligned}
& M^{\prime} \frac{d V}{d t}=10^{-3}\left(F_{v}-F_{k}-W_{o}-W_{d}\right) \\
& V=\frac{d x}{d t},
\end{aligned}
$$

Where: $V[\mathrm{~m} / \mathrm{s}]$ - train speed, $x[\mathrm{~m}]$ - distance, $t[\mathrm{~s}]$ - time, $M^{\prime}$ $\left[\mathrm{t} / \mathrm{m} / \mathrm{s}^{2}\right]$ - weight coefficient of the train, $F_{v}[\mathrm{daN}]$ - tractive effort at the wheel rim, $F_{k}[\mathrm{daN}]$ - braking effort of the train, $W_{o}[\mathrm{daN}]$ - basic train resistance, $W_{d}[\mathrm{daN}]$ - additional resistance.

Additional resistance (Fig. 8) is the one that arises from the line gradient and its curve radius and the basic resistance is the one that arises during the vehicle movement (with defined speed along the straight and horizontal line considering the average weather conditions). $M^{\prime}$ value is as follows:

$$
M^{\prime}=\frac{Q_{L}\left(1+\varepsilon_{L}\right)+Q_{K}\left(1+\varepsilon_{K}\right)}{g}
$$

Where: $Q_{L}[\mathrm{t}]$ - locomotive weight ready for service, $Q_{K}[\mathrm{t}]$ load hauled, $\varepsilon_{L}$ - rotational inertia coefficient of a locomotive, $\varepsilon_{K}$ - rotational inertia coefficient of coaches, $g=9,81\left[\mathrm{~m} / \mathrm{s}^{2}\right]-$ gravitational acceleration.

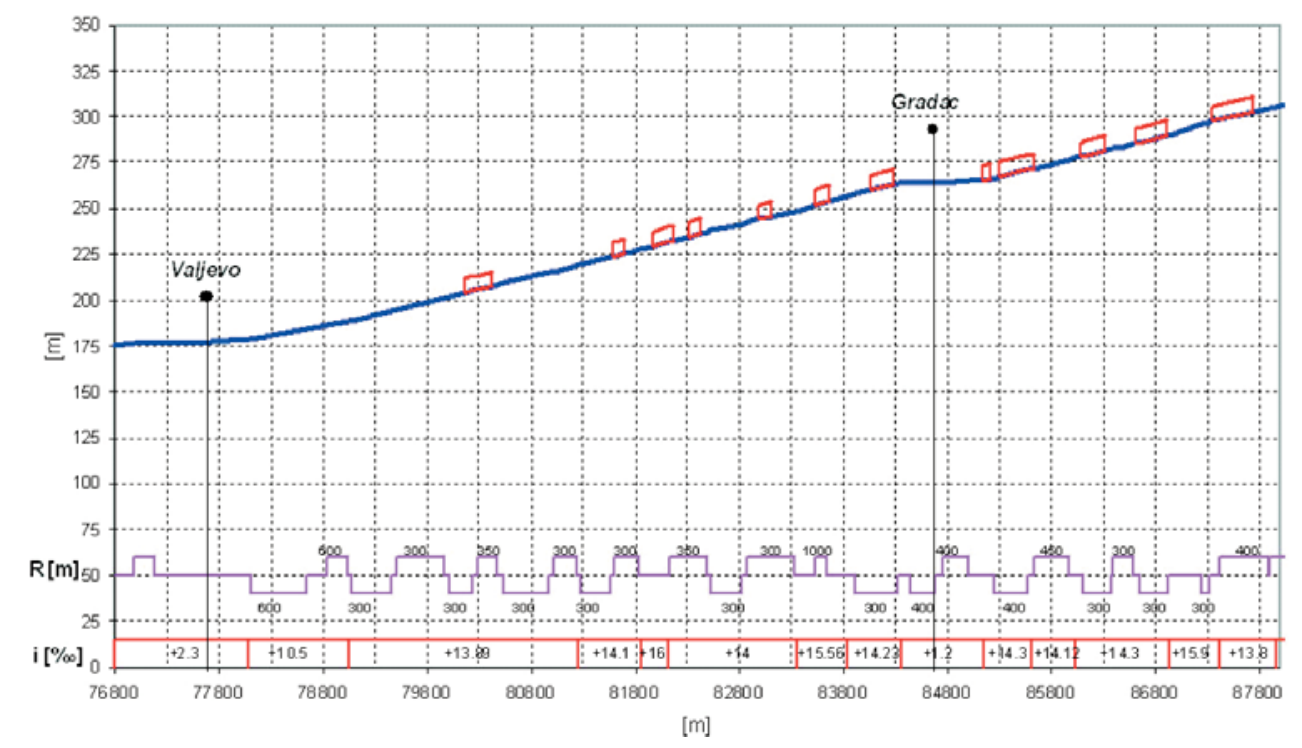

Fig. 8 Additional track resistance 
If we choose $10^{3} / g \sim 10^{2} \mathrm{~s}^{2} / \mathrm{m}$ and if we take specific resistance instead of basic ones the movement differential equation can get the following form suitable for further manipulation:

$$
\begin{aligned}
& 102\left(1+\varepsilon_{V}\right) Q_{V} \frac{d V}{d t}=F_{V}-F_{K}- \\
& -\left(Q_{L} w_{o L}+Q_{K} w_{o K}\right)-Q_{V} w_{d}
\end{aligned}
$$

Where: $\varepsilon_{V}$ - rotational inertia coefficient of a train, $Q_{V}[\mathrm{t}]$ - total train weight, $w_{o L}[\mathrm{daN} / \mathrm{t}]$ - specific basic resistance of locomotive, $w_{d}[\mathrm{daN} / \mathrm{t}]$ - specific additional train resistance, $w_{o K}[\mathrm{daN} / \mathrm{t}]-$ specific basic resistance of railway carriages.

The values $Q_{V}$ and $\varepsilon_{V}$ satisfy the following equation: $Q_{V}=Q_{L}+$ $+Q_{K}, \varepsilon_{V}=\frac{Q_{L} \varepsilon_{L}+Q_{K} \varepsilon_{K}}{Q_{V}}$. This train movement differential equation is used for the calculation of the train running time and traction energy consumption.

\section{The software for electric locomotives runningsimulation}

The software for optimization of the electric locomotive control for the driving energy savings purposes is based on the following methodology elements:

(1) The real problem analysis has taken into consideration numerous factors (parameters) which affect the driving energy consumption (railway line, train type and locomotive series).

(2) During the examination of the relations between the given factors the corresponding functional dependencies were determined and formalized and they represent the mathematical model of the real problem. The basis of this model are the train movement differential equations whose structure is very complex and unsuitable for the use of the well-known analytic methods for their solving. Apart from the differential equations the mathematical model also consists of numerous algebraic, logical and other relations that are needed for better understanding of the real problem.

(3) For the solution of the optimal control problem described with the mentioned mathematical model numerical methods for differential equations solving must be used. Therefore, the RungeKutta method for differential equations of the fourth degree was used. Algorithm also has the procedures for determination of running time, distance, instantaneous speed and acceleration, amount of released energy during electric braking, consumed drive energy and the other factors that concern train running. Calculations are made in the discrete time points (according to the solution of the movement differential equations) from the starting to the stopping time on the given line. Given procedures are done through the following elementary drive regimes: (a) train starting, (b) train acceleration, (c) train movement with maintaining the constant speed by traction or electric resistance or pneumatic brake or combined electric and pneumatic brake, (d) coasting and (e) braking. Every complex drive can be divided into several elemental regimes. Therefore, the global algorithm is made in such a manner that each of the mentioned regimes represents one complete module, which can be activated as needed.

User is offered to choose one of the following ways of train running on the given line: train running with lowest running times and highest driving energy consumption, train running with the limited traction motors current (for instance, $I=1000 \mathrm{~A}$ ), train running with the combination of the lowest running times and the use of inertia where it is possible and technically justified and train running with the limited traction motors current and the use of inertia where it is possible and technically justified.

A keyboard is used for entering parameters that describe each running simulation. Some of them are: name of a line, train form (express, passenger or freight), train weight, train length, locomotive type (441 or 461), maximum locomotive speed, maximum traction motor current, percentage of braking and working variant. All other parameters are grouped in the three input files: train parameters file, file with the data describing the locomotive and the file with the data describing the characteristics of railway line.

As a result of the simulation two files with the .E and .R extensions are made and they hold the important simulation values.

The marks in the data columns from the file with the .E extension (data for stations) have the following meaning: $s[\mathrm{~m}]$ - station distance, $d t$ [min] - running time between stations, $t$ [min] - cumulative running time between stations, $t+5 \%$ [min] - cumulative running time between stations increased for $5 \%$ because of traffic irregularity, $V[\mathrm{~km} / \mathrm{h}]$ - train speed through station, $V_{\max }[\mathrm{km} / \mathrm{h}]-$ maximum permitted train speed through station, $w[\mathrm{daN} / \mathrm{t}]$ - specific basic track resistance, $n$ [1/min] - revolutions per minute of traction motor, $F[\mathrm{kN}]$ - locomotive tractive effort, $I[\mathrm{~A}]$ - traction motor current, $U[\mathrm{~V}]$ - traction motor voltage, $E[\mathrm{kWh}]$ consumed energy for train traction, $R E$ [kWhr] - consumed reactive energy for train traction.

The marks in the data columns from the file with the .R extension (data for travelling regimes) have the following meaning: $s[\mathrm{~m}]$ - distance of changing travelling regimes, $w[\mathrm{daN} / \mathrm{t}]-$ specific basic track resistance, $d t$ [min] - running time between two travelling regimes, $t$ [min] - cumulative running time between two travelling regimes, $t+5 \%$ [min] - cumulative running time between two travelling regimes increased for $5 \%$ because of traffic irregularity, $V[\mathrm{~km} / \mathrm{h}]$ - train speed, $E[\mathrm{kWh}]$ - consumed energy for train traction, $R E[\mathrm{kWhr}]$ - consumed reactive energy for train traction, $I_{k o c}[\mathrm{~A}]$ - braking current of traction motor acting as a generator, $E_{k o c}[\mathrm{kWh}]$ - energy dissipated using electric resistance brake, $T_{k o c}[\mathrm{~min}]$ - time of electric resistance brake usage, $I p[\mathrm{~A}]$ - traction motor excitation current, Travelling regime-corresponding travelling regime. 


\section{Results of simulations and experimental tests}

On the Serbian Railway network there are different lines considering the field configuration: level, mountain and mixed. The Belgrade (Resnik)-Bar line is a typical mountain line with numerous up and downgrades and the small curve radiuses $(R=300 \mathrm{~m})$. This track, which is $405.1 \mathrm{~km}$ long, has 558 changes of specific resistance. The longitudinal line section is adapted for computer simulation by its reduction without connection of the successive related sections. The other line elements, such as: maximum section speeds, train stops in stations, restricted-speed running, etc. are used according to the timetable.

Simulation of various freight trains running hauled by electric locomotives series 441 and 461, is done to estimate the total running time and consumed energy for the train traction. Simulation is done on these lines: Beograd ranzirna "A" - Mala Krsna
$\left(Q_{V}=1160 \mathrm{t}\right)$, Nis - Tabanovci $\left(Q_{V}=1160 \mathrm{t}\right)$, Beograd ranzirna "B" - Lapovo ranzirna $\left(Q_{V}=800 \mathrm{t}\right)$, Mala Krsna - Rakovica $\left(Q_{V}=600 \mathrm{t}\right)$, Resnik - Podgorica $\left(Q_{V}=1000 \mathrm{t}\right.$, Fig. 9,10$)$ and Podgorica - Resnik $\left(Q_{V}=1060 \mathrm{t}\right)$. On the basis of the obtained values we can conclude that average specific consumed energy for the locomotive series 441 is about $25.5 \mathrm{Wh} / \mathrm{brtkm}$ and for the locomotive series 461 is about $35.1 \mathrm{Wh} / \mathrm{brtkm}$ [4]. In the case of passenger trains the specific consumed energy for train traction is higher by about $30 \%$ and more.

The Slovenian Railways have started to install up-to-date digital equipment for metering and reading the energy consumption with the use of the GPS system on electric traction vehicles. The operating principle is shown in Fig. 11.

The following equipment is installed on the locomotive: Energy meter LEM EM4T, voltage transductor type LEM CV 4-6000/SP1,

\begin{tabular}{|c|c|c|c|c|c|c|c|c|c|c|c|c|c|}
\hline $\begin{array}{l}--- \\
\text { STATION } \\
(\text { kWhr })\end{array}$ & $\begin{array}{c}\mathrm{S} \\
(\mathrm{m})\end{array}$ & $\begin{array}{c}d t \\
(\min )\end{array}$ & $\begin{array}{c}t \\
(\min )\end{array}$ & $\begin{array}{l}t+5 \% \\
(\min )\end{array}$ & $\begin{array}{c}\mathrm{V} \\
(\mathrm{km} / \mathrm{h})\end{array}$ & $\begin{array}{c}V \max \\
(\mathrm{km} / \mathrm{h})\end{array}$ & $\begin{array}{c}\mathrm{W} \\
(\mathrm{daN} / \mathrm{t})\end{array}$ & $\stackrel{n}{(1 / \min )}$ & $\begin{array}{l}\mathrm{F} \\
(\mathrm{kN})\end{array}$ & $\begin{array}{c}I \\
(\mathrm{~A})\end{array}$ & $\begin{array}{c}\mathrm{U} \\
(\mathrm{V})\end{array}$ & $\begin{array}{c}E \\
(k W h)\end{array}$ & $\mathrm{RE}$ \\
\hline--- & & & & & & & & & & & & & \\
\hline $\begin{array}{l}\text { Resnik } \\
0.0\end{array}$ & 0 & 0.00 & 0.00 & 0.00 & 0.0 & 0 & 3.12 & 0.0 & 0.00 & 0.0 & 0.0 & 0.0 & \\
\hline $\begin{array}{l}\text { Bela Reka } \\
288.5\end{array}$ & 7632 & 7.00 & 7.00 & 7.34 & 69.5 & 70 & 2.50 & 1112.2 & 43.74 & 355.5 & 393.2 & 417.3 & \\
\hline $\begin{array}{lll}- & - & - \\
-\end{array}$ & --- & $-\quad-$ & --- & --- & $-\quad--$ & $-\quad-$ & $-\quad-$ & -- & $-\quad-$ & $-\quad-$ & $-\quad-$ & --- & \\
\hline $\begin{array}{l}\text { Bioce } \\
8672.8\end{array}$ & 389571 & 8.42 & 324.33 & 340.55 & 74.5 & 75 & -1.08 & 1192.4 & 17.71 & 247.4 & 307.6 & 12462.0 & \\
\hline $\begin{array}{l}\text { Podgorica } \\
8804.0\end{array}$ & 405100 & 12.00 & 336.33 & 353.15 & 0.0 & 0 & 0.00 & 0.0 & 0.00 & 0.0 & 0.0 & 12644.5 & \\
\hline
\end{tabular}

Fig. 9 Data for stations

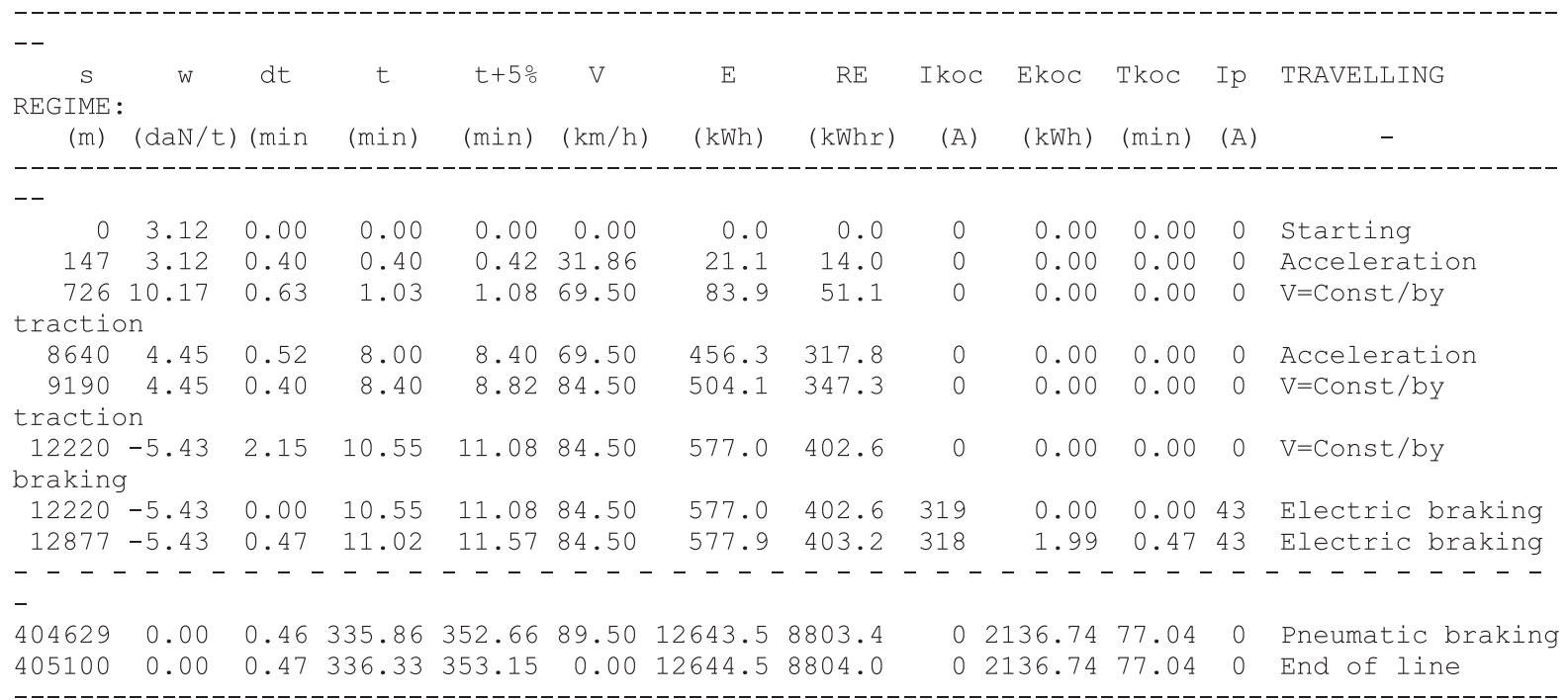

Fig. 10 Data for travelling regimes 


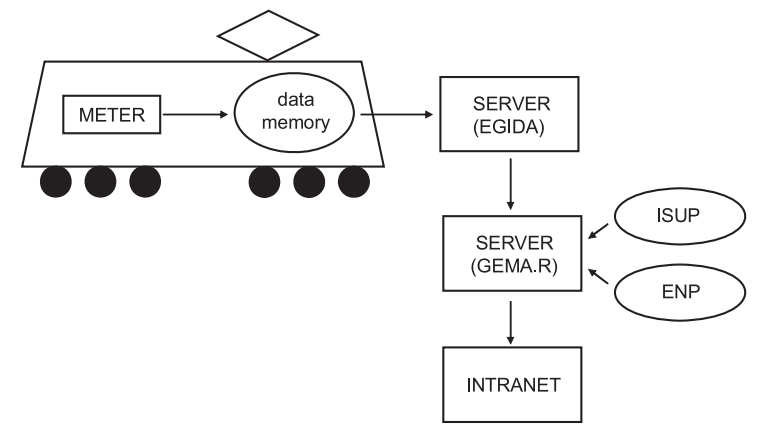

Fig. 11 Measuring of consumption of energy on electric locomotives on Slovene railways

and current transductor type LF 2005-S/SP9. The consumed energy is read by the data memory, in which the data on consumed energy and data from GPS are combined. These data are sent to the server EGIDA (where the data of all electric locomotives are collected). From there the data are sent to the server GEMA.R, which unites all the data from the information system of traffic performance (ISUP) and from railway substations (ENP). The data on the consumer are sent to the INTRANET [5].

In the continuation, the analysis of the run of the train No. 47408 , with a mass of 1708 tons and with a locomotive series 363 - 004 is shown for the trip from Ljubljana to Maribor on 14 September 2007. For better understanding the analysis of energy consumption of this train is given only for the distance travelled from Ljubljana to Ljubljana Moste (Table 1) [6].

Analysis of electricity consumption at train 47408 on railway line Ljubljana - Ljubljana Moste

Table 1

\begin{tabular}{|c|c|c|c|c|c|}
\hline $\begin{array}{c}\text { Consumed } \\
{[\mathrm{kWh}]}\end{array}$ & $\begin{array}{c}\text { Regenerated } \\
{[\mathrm{kWh}]}\end{array}$ & $\begin{array}{c}\text { Track } \\
\text { section }\end{array}$ & $\begin{array}{c}\text { Speed } \\
{[\mathrm{km} / \mathrm{h}]}\end{array}$ & $\begin{array}{c}\text { Width } \\
{[\mathrm{m}]}\end{array}$ & $\begin{array}{c}\text { Length } \\
{[\mathrm{m}]}\end{array}$ \\
\hline 1 & 0 & Ljubljana & 0 & 46.0588 & 14.5267 \\
\hline 1 & 0 & Ljubljana & 0 & 46.0588 & 14.5267 \\
\hline 0 & 0 & Ljubljana & 17 & 46.0588 & 14.5279 \\
\hline 20 & 0 & $\begin{array}{c}\text { Ljubljana }- \\
\text { Ljubljana } \\
\text { Moste }\end{array}$ & 35 & 46.0589 & 14.5339 \\
\hline
\end{tabular}

The fifth and the sixth column in the table represent the width and the length of data acquisition from the locomotive by the GPS equipment. The GPS system divides the area of movement of the locomotive into small squares and each such square indicates transmitted information about the energy consumed from the locomotive to the centre. It must be taken into consideration that the GPS does not recognize the curve of the railway track in the moment of reading, but it works along the bee-line. Therefore the accuracy of this system amounts to approximately $94 \%$. If the number of squares is increased, the squares become smaller and a more accurate result is obtained.

Over the total distance of $156 \mathrm{~km}$ the electric energy consumption for this train was $2893 \mathrm{kWh}$. This energy consumption amounts only to $10.89 \mathrm{Wh} / \mathrm{brtkm}$ which is much less than average consumption of $35.1 \mathrm{Wh} / \mathrm{brtkm}$ with 461 series locomotives. This is due to differences in railway line difficulty. Line Ljubljana - Maribor has no ascending slopes, for the most part there is a downgrade of $10 \%$. Lines of the Serbia railways, for which these measurements are made, are mainly steep with a slope up to $27 \%$.

Line Koper - Divaca in Slovenija with a slope up to $26 \%$ energy consumption with 363 series locomotives amounts about $45 \mathrm{Wh} / \mathrm{brtkm}$.

\section{Conclusion}

The software for the electric locomotive optimization control for driving energy savings purposes enables the user to find the optimal combination (according to his needs) of the changeable train traction parameters. Almost every train traction parameter is changeable: locomotive series with all characteristic parameters (wheel usage percentage, rotation masses affect factor, nominal traction motors voltage value, continuous and maximum traction motors current, efficiency of cog-wheels, deformation factor, locomotive active and apparent power on the pantograph, etc.), line elements (maximum speeds, stopping, restricted-speed running, length of stops in stations, track resistance, etc.). The amount of the output results is bigger than in all the other projects done so far. The train running simulation time is considerably shorter than in all other traction-energy calculation methods known so far. The simulation results can also be used for making the regime card of each train run in the whole timetable diagram.

In order to verify in practice the calculated driving energy consumption of electric locomotives at the Serbian Railway numerous measurements are conducted on the tracks. These measurements show high coincidence between theoretical and practical results.

The software for train driving energy consumption is also applied on the diesel locomotives and the only electric-motor train series ZS 412/416 for urban-suburban traffic on the Serbian Railways.

For this manner of analysis of consumption electricity energy are decided in Slovenia because of larger number of carriers. 


\section{References}

[1] RADOSAVLJEVIC, A. et al.: Optimization of Running Electric Locomotives Series 441 Because of Driving Energy Savings (in Serbian), SI CIP Belgrade, 1991

[2] RADOSAVLJEVIC, A., MILUTINOVIC, D., BECEJAC, L.: Simulation of Electric Locomotives Running for the Driving Energy Savings Purposes, Fourth International Conference Drives and Supply Systems for Modern Electric Traction in Integrated $21^{\text {st }}$ Century Europe, Warsaw, Poland, 23-25 September 1999, pp. 226-230, 1999

[3] RADOSAVLJEVIC, A., KOZULJ, T., BECEJAC, L.: Technical and Operational Characteristics of Traction Units on Yugoslav Railways (in Serbian), Zelnid, Belgrade, 1998

[4] RADOSAVLJEVIC A, MILUTINOVIC, D., JOVANOVIC, R., LUCANIN, V.: Experimental Determination of Mixed Feight Train Running Resistance and Influence on Energy Consumption, $6^{\text {th }}$ World Congress on Railway Research WCRR 2003 - Topic: Interactive Systems and Environment - Session: Energy Emissions, Edinburgh, Scotland, 2003, pp. 40-47, 2003

[5] DREMELJ, B.: Onboard Metering Electricity Consumption System Architecture and Data Paths (in Slovenian), 2006

[6] Slovene Railways, Intranet - Data Concerning Train, No 47408 from day 14.09.2007. 